\title{
Turnos ininterruptos de revezamento
}

\author{
Continuous relay shifts
}

\author{
HELENA KUgel LAZZARINa \\ VINÍCIUS HERNANDES ${ }^{b}$
}

\begin{abstract}
RESUMO
O presente artigo faz uma análise ao sistema de turnos ininterruptos de revezamento, explicitando o seu conceito, as vantagens desta jornada especial, bem como os requisitos para a sua caracterização. Aborda, ainda, a sua aplicação no caso concreto, ou seja, como é dada a concessão de intervalos e de folgas, como é aplicada a hora noturna, como o conceito de turno é fixado para poder enquadrar os trabalhadores nesta modalidade ou não e, por fim, como é realizada a remuneração destes trabalhadores.
\end{abstract}

Palavras-chave: Turnos. Revezamento. Ininterrupção.

\begin{abstract}
This paper presents an analysis of the continuous RELAY shifts system, explaining the concept, the advantages of this special day, as well as requirements for its characterization. Addresses also its application in this case, that is, as given intervals and the granting of clearances, as applied to night time, as the concept of power shift is fixed to frame the workers in this mode or not and, finally, the pay of those workers as performed.
\end{abstract}

Keywords: Turns. Relay. Uninterrupted.

\section{INTRODUÇÃO}

O presente trabalho versa sobre turnos ininterruptos de revezamento, figura jurídica caracterizada no artigo $7^{\circ}$, XIV, da Constituição Federal. Inicialmente, são expostas as características da figura, os requisitos necessários para ser configurada tal jornada especial, entre outros aspectos.

Em um segundo momento, analisa-se a aplicação desta figura, como é realizada no caso de concessão de intervalos, concessão de folgas, como é entendida a hora noturna neste caso específico. Por fim, são estudadas as normas para a fixação do turno, conceito essencial para o debate do tema, e como é realizada a remuneração dos trabalhadores que se enquadram nesse sistema organizacional.

\section{CARACTERIZAÇÃO DA FIGURA JURÍDICA}

Os turnos ininterruptos de revezamento estão previstos no artigo 7으, XIV, da Constituição Federal ${ }^{1}$. Enquadra-se nesse tipo legal o sistema de trabalho que coloque o empregado, de forma alternada, em cada semana, quinzena ou mês, em contato com diferentes fases do dia e da noite. ${ }^{2}$ Tem-se a ideia de falta de interrupção no sistema de trabalho, sob a ótica do trabalhador.

Cabe ponderar, entretanto, que o TST, em orientação jurisprudencial, ${ }^{3}$ permite a configuração dos turnos ininterruptos de revezamento ainda que os horários não cubram todos os momentos do dia e da noite, mas o façam de modo parcial. Contudo, o

\footnotetext{
a Advogada, graduada na Faculdade de Direito da PUCRS. Especializanda em Direito e Processo do Trabalho, curso de Pós-Graduação em Direito da PUCRS $<$ helenalazzarin@gmail.com>.

b Advogado, graduado na Faculdade de Direito da PUCRS. <throua@hotmail.com>.
} 
contato com os diversos horários do dia e da noite é significativo - mesmo que não seja integral ${ }^{4}$.

Ainda, vale lembrar que é irrelevante que a atividade da empresa se desenvolva de forma ininterrupta ${ }^{5}$, ou seja, para fins de tipificação da presente figura jurídica, não importa a existência de paralisação na empresa, total ou parcial, fixa ou móvel, em um dia da semana. $\mathrm{O}$ que vale é o trabalho e a figura do trabalhador - o direito à jornada especial é constituído em virtude do maior desgaste a que se submete o obreiro posicionado nesse sistema de organização laboral ${ }^{6}$.

Faz jus a jornada especial concedida a estes trabalhadores, uma vez que, biologicamente, o ser humano é influenciado pela luz solar, estando submetido a um ritmo circadiano - ou, em linguagem popular, a um "relógio biológico". Esse ritmo regula a cadência física e psicológica do corpo humano, influenciando fortemente na fadiga muscular, na disposição para o trabalho, etc. ${ }^{7}$ É natural que o trabalhador submetido ao sistema de revezamento de turnos sinta um desgaste físico e psíquico maior do que os demais.

\section{APLICAÇ̃̃O - CONCESSÃO DE INTERVALOS E DE FOLGAS}

\subsection{Concessão de intervalos}

Anteriormente havia uma controvérsia acerca da concessão de intervalos intrajornada aos empregados que laboravam em turnos ininterruptos de revezamento com relação a uma possível descaracterização desta jornada, uma vez que, segundo Nascimento8 "como a Lei Magna referiu-se a turnos ininterruptos, surgiu um entendimento segundo o qual se a empresa concede intervalos na jornada de trabalho, não se configura a hipótese de jornada normal de 6 horas diárias".

De acordo com Martinez" "a ideia inicial seria a de que existiria tal instituto nas situações em que um trabalhador, de modo ininterrupto, isto é, sem qualquer parada, alternasse seus turnos, num sistema de revezamento".

Porém, a concessão de intervalos intrajornadas aos trabalhadores é norma de ordem pública, disposta no artigo 71 e $\S 1^{\circ}$ da Consolidação das Leis do Trabalho com a seguinte redação:

Art. 71. Em qualquer trabalho contínuo, cuja duração exceda de 6 (seis) horas, é obrigatória a concessão de um intervalo para repouso ou alimentação, o qual será, no mínimo, de 1 (uma) hora e, salvo acordo escrito ou contrato coletivo em contrário, não poderá exceder de 2 (duas) horas. (grifou-se)

$\S 1^{\circ}$ Não excedendo de 6 (seis) horas o trabalho, será, entretanto, obrigatório um intervalo de 15 (quinze) minutos quando a duração ultrapassar 4 (quatro) horas.
Godinho Delgado ${ }^{10}$ faz referência ao motivo da importância do gozo deste tipo de intervalo por parte do empregado ao dizer que:

Visam tais lapsos de descanso situados dentro da jornada de trabalho, fundamentalmente, a recuperar as energias do empregado, no contexto da concentração temporal de trabalho que caracteriza a jornada cumprida a cada dia pelo obreiro. Seus objetivos, portanto, concentram-se, essencialmente em torno de considerações de saúde e segurança do trabalho, como instrumento relevante de preservação da higidez física e mental do trabalhador ao longo da prestação diária de serviços.

Sendo assim, é possível perceber que o dispositivo legal da CLT em questão está em consonância com a Constituição Federal/88, que em seu artigo 7º, XXII dispõe ser um direito dos trabalhadores a "redução dos riscos inerentes ao trabalho, por meio de normas de saúde, higiene e segurança".

Desta forma, claramente se percebe que tais trabalhadores também possuem direito ao necessário tempo para repouso e alimentação, de forma que a sua concessão não descaracteriza o regime de turnos ininterruptos de revezamento.

É importante salientar que tal entendimento está sumulado pelo Tribunal Superior do Trabalho desde 1997. Na época, a Orientação Jurisprudencial $n^{0} 78$ daquele Órgão tinha a seguinte redação:

A interrupção do trabalho dentro de cada turno ou semanalmente, não afasta a aplicação do art. $7^{\circ}$, XIV, da CF/1988.

Após, com a Resolução 79/1997, a mesma foi convertida na Súmula no 360 que passou a dizer:

A interrupção do trabalho destinada a repouso e alimentação, dentro de cada turno, ou o intervalo para repouso semanal, não descaracteriza o turno de revezamento com jornada de 6 horas previsto no art. $7^{\circ}$, inciso XIV, da Constituição da República de 1988.

Posteriormente, o Supremo Tribunal Federal, no ano de 2003, também se manifestou através da Súmula no 650 que diz:

Os intervalos fixados para descanso e alimentação durante a jornada de seis horas não descaracterizam o sistema de turnos ininterruptos de revezamento para o efeito do art. $7^{\circ}$, XIV da Constituição. 
Desta maneira, no mesmo ano de 2003 o TST, através da Resolução no 121/2003 resolveu manter o já citado enunciado 360 .

Ainda, outro aspecto importante a ser considerado para a concessão de intervalos intrajornada aos trabalhadores em turnos ininterruptos de revezamento está no fato de que, conforme menciona Martins ${ }^{11}$, " $a$ ininterruptividade diz respeito à operacionalização da empresa, ao revezamento, à alternância de turnos, e não ao intervalo para repouso ou alimentação concedido na jornada de trabalho", ou seja, não há o que confundir a necessidade do empreendimento com a do empregado.

Portanto, no que se relaciona à concessão de intervalos intrajornadas ao trabalhador em turnos ininterruptos de revezamento, é de se referir que não havendo a concessão total do período para repouso e alimentação por parte de empregador ao seu empregado, passa a aplicar-se o art. 71, §4을 CLT e Súmula 437, I do TST para determinar o pagamento de horas extras, com adicional de $50 \%$ relacionado a todo o tempo não usufruído nos termos da jurisprudência do TRT4:

RECURSOS ORDINÁRIOS DA RECLAMADA E DO RECLAMANTE. ANÁLISE CONJUNTA. MATÉRIA COMUM. TURNOS ININTERRUPTOS DE REVEZAMENTO. HORAS EXTRAS. Previsão em norma coletiva a validar a jornada de oito horas para o trabalho em turnos ininterruptos de revezamento. Diferenças de horas extras que se evidenciam pelo cotejo entre os controles de horário e os recibos de pagamento.

INTERVALOS INTRAJORNADA. Inválida a cláusula coletiva que prevê a redução dos intervalos intrajornada, consoante entendimento expresso na Orientação Jurisprudencial $\mathrm{n}^{\circ} 342$ da SDI-I do TST e na Súmula no 38 deste Regional. Devido o pagamento como hora extra, de todo o periodo. Exegese do artigo 71, § 4⿳亠丷, da CLT e da Súmula $n^{\circ}$ 437, item I, do TST. Ademais, os intervalos em questão possuem natureza salarial, nos termos da Orientação Jurisprudencial no 354 da SDI-I, sendo devidas as integrações em parcelas de mesma natureza. (RO 0001816-21.2010.5.04.0231, Relatora MARIA DA GRAÇA RIBEIRO CENTENO, data 31/10/2012) (grifou-se)

De outra forma, como visto, ainda que seja concedido ao trabalhador o intervalo para repouso e alimentação, será o caso de haver o pagamento de horas extraordinárias de todas aquelas que excederem a sexta diária nos termos do art. 7º, XVI da CF/88.

Com relação a este pagamento, Godinho Delgado ${ }^{12}$ faz referência ao fato de que embora o empregado labore em turnos ininterruptos, mas realize jornada de 8 horas diárias e 44 semanais, há duas linhas de entendimento na jurisprudência quanto a remuneração destas horas extraordinárias:

[...] A primeira vem insistindo que será devido a esse trabalhador apenas o respectivo adicional de sobrejornada, calculado sobre a $7^{\mathrm{a}} \mathrm{e}$ $8^{\mathrm{a}}$ horas laboradas. Argumenta essa vertente que o obreiro já teria recebido, integrado a seu salário o valor principal de tais horas (aplicando-se, em suma, à situação a situação em exame o critério tradicionalmente previsto na Súmula 85, TST).

A segunda corrente interpretativa aponta insuplantáveis problemas na linha de reflexão anteriormente exposta. Argumenta que a primeira corrente não percebe, na verdade, que a Constituição, ao reduzir a jornada, elevou o preço relativo da força de trabalho submetida a turnos ininterruptos de revezamento: noutras palavras, elevou o salário hora desses trabalhadores. Desse modo, o salário hora correspondente a 8 horas diárias (e 44 na semana) é significativamente inferior ao salário hora relativo a 6 horas diárias de trabalho (e 36 na semana). Para a segunda vertente, o critério jurisprudencial aplicável à presente situação seria, pois, o da Súmula 199, I, TST (que menciona a ineficácia da prática de pré-contratação de horas extras, determinando que se pague, em separado, a efetiva sobrejornada). Não se aplicaria, aqui, portanto, o critério da Súmula 85, III (que se refere a pagamento de adicional em regimes de compensação de jornada irregulares - situações em que houve, de fato, a correta percepção das horas trabalhadas, se considerada a semana ou o mês).

O mesmo autor afirma dever-se aplicar o disposto pela segunda corrente ${ }^{13}$, com o pagamento das horas extras com adicional de $50 \%$ ao empregado.

\subsection{Concessão de Folgas}

A Constituição Federal ao trazer, de forma expressa, no seu artigo 7ํㅡ, XV a obrigatoriedade do "repouso semanal remunerado, preferencialmente aos domingos", garantiu o direito a concessão de folgas a todos os trabalhadores.

Diante deste fato, importante destacar Martins ${ }^{14}$ :

Dizer que, se a empresa não trabalha aos domingos ou, o empregado tem folga nesse dia, haveria a desconfiguração do turno ininterrupto de revezamento é uma afirmação falaciosa [...]. $\mathrm{O}$ fato de a empresa conceder folga no domingo ou em outros dias, de maneira a compensar a folga que foi trabalhada, não vai descaracterizar o turno ininterrupto de revezamento, pois pode ser decorrente de circunstâncias técnicas da empresa, da própria produção, além de atender a preceito constitucional e legal. 
Como anteriormente já afirmado, a ininterruptividade do turno está diretamente relacionada à situação operacional da empresa, uma vez que há vantagens econômicas para determinados empreendimentos funcionarem de maneira contínua e não ao empregado que, ao laborar em constantes situações de mudanças no seu turno de trabalho sofre diversos tipos de prejuízos, como aqueles de ordem física, psicológica e familiar.

Nesse sentido vai Delgado ${ }^{15}$ quando aduz que "não prejudica a tipificação dos turnos ininterruptos de revezamento a existência, na empresa, de paralização total ou parcial, fixa ou móvel, em um dia da semanapara atender, por exemplo, conjuntamente, ao repouso semanal remunerado".

A seguinte jurisprudência do Tribunal Superior do Trabalho define a situação exposta:

AGRAVO DE INSTRUMENTO. RECURSO DE REVISTA. TURNO ININTERRUPTO DE REVEZAMENTO.

A concessão de folgas durante a semana, de intervalo intrajornada e o labor pelo reclamante em duas jornadas, não descaracterizam o turno ininterrupto de revezamento. A ininterruptividade a que alude o art. $7^{\mathrm{O}}$, inciso XIV, da Carta Magna, refere-se à operacionalização da empresa. Ou seja, basta que a atividade empresarial seja contínua, ininterrupta, com os empregados cumprindo jornada de trabalho em sistema de escalas, para que esteja configurado o regime de turnos ininterruptos de revezamento, com jornada de 6 horas diárias.

Esse entendimento encontra-se sintetizado na Súmula 360/TST, o que inviabiliza o conhecimento do recurso, nesse tema, ante os termos dos arts. 896, $\S \S 4^{\circ}$ e 5 , da CLT, e do Enunciado no 333 do TST.

DA DOBRA DAS FOLGAS OCORRIDAS APÓS O SÉTIMO DIA.

A lei obriga que durante a semana civil (dentro de 7 dias que compreendem uma semana), preferencialmente no domingo, seja concedido o repouso semanal remunerado. Procedimento em contrário afronta o artigo $1^{\circ} \mathrm{o}$ da Lei $n^{\circ}$ 605/49, bem como o inciso XI do artigo $7^{\circ}$ da Constituição Federal em vigor.

As normas de repouso são de ordem pública e não permitem tergiversações, não havendo, portanto, ofensa ao dispositivo legal apontado.

Agravo a que se nega provimento. (AIRR 305900-74.2000.5.15.0024, Relator(a): RIDER DE BRITO, Julgamento: 19/11/2003, Órgão Julgador: $5^{\text {a }}$ Turma) (grifou-se)

A Instrução Normativa no 01/1988 do Ministério do Trabalho, ao fixar a ação fiscal a ser desenvolvida pelos Fiscais do Trabalho em face da Constituição Federal determinava que, ocorrendo turnos ininterruptos de trabalho, a jornada seria de 6 horas, devendo ocorrer conjuntamente alguns fatores, dentre eles o fato de "que o revezamento seja ininterrupto, isto é, não sofra solução de continuidade no período de 24 (vinte e quatro) horas, independente de haver, ou não, trabalho aos domingos."

Posteriormente, outra Instrução Normativa, a de no 64/2006 do Ministério do Trabalho que trata especificamente sobre a fiscalização em empresas que laboram em turnos ininterruptos de revezamento, define expressamente no art. $2^{\mathrm{o}}$ que "considera-se trabalho em turno ininterrupto de revezamento aquele prestado por trabalhadores que se revezam nos postos de trabalho nos horários diurno e noturno em empresa que funcione ininterruptamente ou não", ou seja, também passa a deixar claro que o fato do estabelecimento interromper, por qualquer motivo suas atividades, não enseja a descaracterização deste regime.

Sendo assim, não havendo a concessão das folgas constitucionalmente previstas no art. 7o, $\mathrm{XV}^{16}$, é o caso de aplicar-se, também a estes trabalhadores, o pagamento em dobro de tais dias laborados, conforme o disposto na Orientação Jurisprudencial no 410 da SDI-I do Tribunal Superior do Trabalho:

REPOUSO SEMANAL REMUNERADO. CONCESSÃO APÓS O SÉTIMO DIA CONSECUTIVO DE TRABALHO. ART. 7으, XV, DA CF. VIOLAÇÃO. Viola o art. $7^{\circ}, \mathrm{XV}$, da CF a concessão de repouso semanal remunerado após o sétimo dia consecutivo de trabalho, importando no seu pagamento em dobro.

A jurisprudência do TRT4 é nesse sentido:

REPOUSO SEMANAL REMUNERADO. CORSAN. Os arts. $7^{\circ}, \mathrm{XV}$, da $\mathrm{CF}$ e $1^{\circ} \stackrel{\mathrm{O}}{\text { da Lei } \mathrm{n}^{\circ}}$ 605/49, aliados ao art. 67 da CLT, sem excluir a hipótese de trabalho em turnos ininterruptos de revezamento, preveem o direito ao repouso semanal remunerado, o que significa que, a cada semana de serviços prestados, assiste ao empregado o direito a um dia de descanso. Logo, a teor do disposto na Orientação Jurisprudencial no 410 da SDI-I do TST, quando irregulares as folgas, ou seja, quando concedidas após o $7^{\circ}$ dia consecutivo de trabalho, é devido o pagamento em dobro do repouso semanal remunerado. Parcialmente provido o recurso do reclamante. (RO 0001391-87.2011.5.04.0512, Relator MARÇAL HENRI DOS SANTOS FIGUEIREDO, data: 14/03/2013)

Esta situação demonstra a necessidade de empresa conceder e do empregado usufruir dos necessários repousos semanais remunerados. 


\section{HORA NOTURNA}

Como já mencionado, o empregado que labora em turnos ininterruptos de revezamento necessita prestar seus serviços em horários alternados, razão pela qual em diversas oportunidades o trabalho acontecerá em períodos noturnos, considerados pelo art. $73, \S 2^{\mathrm{O}}$ da CLT como aquele "executado entre as 22 horas de um dia e as 5 horas do dia seguinte."

Salienta-se que inicialmente os empregados deste tipo de jornada laboral não recebiam o devido adicional de $20 \%$ disposto na CLT, uma vez que o art. $73^{17}$ excluía tal vantagem aos trabalhadores em turnos ininterruptos de revezamento.

Porém, tal controvérsia passou a ser dirimida através da Súmula $\mathrm{n}^{\mathrm{o}} 213$ do Superior Tribunal Federal que dispunha ser "devido o adicional de serviço noturno, ainda que sujeito o empregado ao regime de revezamento". Atualmente, com a garantia da Constituição Federal em seu art. 7ํㅡ, IX, de que a todos os trabalhadores é garantida "remuneração do trabalho noturno superior à do diurno" tal situação foi devidamente resolvida.

Outro debate relacionado ao horário noturno dos trabalhadores em turnos ininterruptos diz respeito à hora ficta disposta no art. 73, $\S 1^{0} 18$ da CLT. Luciano Martinez ${ }^{19}$ defende que a hora de 52 minutos e 30 segundos não deva ser aplicada a estes empregados:

A justificativa provém de uma circunstância bem evidente: as horas noturnas laboradas nesse regime especial têm a dimensão ordinária de sessenta minutos, ao contrário do que se dá com os demais trabalhadores urbanos, que fruem de 52 minutos e 30 segundos por hora laborada, e isso acontece justamente para evitar uma diferenciação interna entre turnos de trabalho. Nestes termos, o privilégio de uma jornada especial absorveria outras vantagens outorgadas aos trabalhadores inseridos em tal situação.

Ainda, pode-se fazer referência a Súmula 112 do TST que faz distinção a determinada classe de trabalhadores:

TRABALHO NOTURNO. PETRÓLEO (mantida) - Res. 121/2003, DJ 19, 20 e 21.11.2003

O trabalho noturno dos empregados nas atividades de exploração, perfuração, produção e refinação do petróleo, industrialização do xisto, indústria petroquímica e transporte de petróleo e seus derivados, por meio de dutos, é regulado pela Lei no 5.811 , de 11.10.1972, não se lhe aplicando a hora reduzida de 52 minutos e 30 segundos prevista no art. $73, \S 1^{\circ}$, da CLT.
Ocorre que este entendimento é minoritário, havendo manifestação do próprio TST quanto aos demais trabalhadores, bem como do Supremo Tribunal Federal.

O STF, através da Súmula nํ2 214, menciona que " $a$ duração legal da hora de serviço noturno (52 minutos e 30 segundos) constitui vantagem suplementar que não dispensa o salário adicional.".

Já o TST passa a garantir a hora noturna reduzida aos trabalhadores em turnos ininterruptos com a OJ no 395 da SDI-I:

TURNO ININTERRUPTO DE REVEZAMENTO. HORA NOTURNA REDUZIDA. INCIDÊNCIA (DEJT divulgado em 09, 10 e 11.06.2010).

$\mathrm{O}$ trabalho em regime de turnos ininterruptos de revezamento não retira o direito à hora noturna reduzida, não havendo incompatibilidade entre as disposições contidas nos arts. $73, \S 1^{\circ}$, da CLT e $7^{\circ}$, XIV, da Constituição Federal.

Desta forma, aos trabalhadores que laboram em turnos ininterruptos de revezamento, é o caso de ser devido tanto o pagamento do adicional de $20 \%$, bem como deve ser observada a hora ficta noturna.

\section{FIXAÇÃO DO TURNO}

É possível a mudança do regime de turnos ininterruptos de revezamento para uma jornada de trabalho "tradicional" por parte do empregador.

Martins $^{20}$ afirma:

A fixação do turno importa, inclusive, numa posição mais benéfica ao trabalhador, que não tem de prestar serviços uma semana pela manhã, noutra à tarde e na seguinte à noite, propiciando-lhe melhores condições biológicas e físicas de trabalho.

Assim, tal situação, por se tratar do jus variandi do empregador, ou seja, de acordo com Delgado ${ }^{21}$ ser aquele "conjunto de prerrogativas empresariais de, ordinariamente, ajustar, adequar e até mesmo alterar as circunstâncias e critérios de prestação laborativa pelo obreiro, desde que sem afronta à ordem normativa ou contratual" não viola o disposto no artigo $468^{22}$ da CLT (o qual trata da alteração do contrato de trabalho do empregado), da mesma forma que não há o que se falar de afronta ao art. 5ำ XXXVI ${ }^{23}$ da Constituição Federal/88 (diante de eventual discussão acerca de direito adquirido por parte destes trabalhadores).

Tal situação já era aplicada aos petroleiros, uma vez que o art. 10, §único da Lei 5.811/72 já referia 
que "não constituirá alteração ilícita a exclusão do empregado do regime de revezamento".

Inclusive a Súmula 391, II do TST é neste sentido:

PETROLEIROS. LEI № 5.811/72. TURNO ININTERRUPTO DE REVEZAMENTO. HORAS EXTRAS E ALTERAÇÃO DA JORNADA PARA HORÁRIO FIXO (conversão das Orientações Jurisprudenciais nos 240 e 333 da SBDI-1) Res. 129/2005, DJ 20, 22 e 25.04.2005.

II - A previsão contida no art. 10 da Lei $\mathrm{n}^{-}$ 5.811/1972, possibilitando a mudança do regime de revezamento para horário fixo, constitui alteração lícita, não violando os arts. 468 da CLT e 7º, VI, da CF/1988. (ex-OJ no 333 da SBDI-1 - DJ 09.12 .2003 )

Sendo assim, salienta-se que havendo tal mudança com fixação de turno, o empregado passa a não fazer mais jus à jornada de 6 horas constitucionalmente estabelecida.

\section{REMUNERAÇÃO DOS TRABALHADORES}

A Constituição Federal no seu artigo 7º, XIV fixa a jornada de trabalho dos empregados em regime de turnos ininterruptos de revezamento ao referir que a estes, será a mesma de seis horas, "salvo negociação coletiva".

Desta afirmação de pode concluir que a partir da $7^{a}$ hora laborada, o trabalhador passa a ter direito a horas extras e ao pagamento de seu respetivo adicional, nos termos do inciso XVI, do art. $7^{\circ}$ da $\mathrm{CF} / 88$. Destaca-se a referencia feita por Martins ${ }^{24}$ no sentido que nestes casos " $n a \tilde{o}$ pode prevalecer a orientação da $S .85$ do TST, que manda pagar apenas o adicional de horas extras."

Martins $^{25}$ ainda faz as seguintes considerações quanto ao empregado que recebe por hora:

Quando o empregado é horista, só é pago o adicional, pois o trabalhador ganha por hora. Para o cálculo do salário-hora do empregado horista, submetido a turnos ininterruptos de revezamento, considerando a alteração da jornada de 8 para 6 horas diárias, aplica-se o divisor 180, em observância ao disposto no art. 7ํㅡ, VI, da Constituição, que assegura a irredutibilidade salarial (OJ 396 da SBDI-1 do TST).

Já Martinez traz a razão desta diferenciação ao horistas neste tipo de regime laboral:
Os empregados que trabalham em turnos ininterruptos de revezamento foram protegidos contra a redução salarial no momento em que o constituinte de 1988 resolveu outorgar-lhes a vantagem de uma jornada reduzida. Foi-lhes proporcionada naquele momento não apenas redução de número de horas trabalhadas por dia (de 8 para 6), mas também, evidentemente, a do divisor para cálculo do salário-hora (de 240 para 180).

Aos empregados que exercem suas atividades em turnos ininterruptos de revezamento, também é de salientar a necessidade de observância do período de intervalo interjornada, conforme o art. 66 da CLT, o qual menciona que "entre 2 (duas) jornadas de trabalho haverá um periodo mínimo de 11 (onze) horas consecutivas para descanso."

Isso porque a Súmula 110 do Tribunal Superior do Trabalho tem a seguinte disposição:

JORNADA DE TRABALHO. INTERVALO (mantida) - Res. 121/2003, DJ 19, 20 e 21.11.2003

No regime de revezamento, as horas trabalhadas em seguida ao repouso semanal de 24 horas, com prejuízo do intervalo mínimo de 11 horas consecutivas para descanso entre jornadas, devem ser remuneradas como extraordinárias, inclusive com o respectivo adicional.

Assim, havendo a falta de concessão deste intervalo aos trabalhadores em turnos ininterruptos de revezamento, também a eles é devido o pagamento de horas extras com o adicional correspondente.

\section{CONCLUSÃO}

Assim, vê-se que os trabalhadores submetidos ao sistema de turnos ininterruptos de revezamento sistema de trabalho no qual os empregados, de forma alternada, em cada semana, quinzena ou mês, entram em contato com diferentes fases do dia e da noite têm uma jornada especial, vale dizer, uma vantagem, em decorrer do desgaste físico causado pela mudança do horário de trabalho, ainda que estes horários sejam parciais. O TST, em orientação jurisprudencial, permite a configuração dos turnos ininterruptos de revezamento ainda que os horários não cubram todos os momentos do dia e da noite, mas o façam de modo parcial.

O fundamento da concessão desta jornada especial ao trabalhador é o natural desgaste físico e psíquico experimentado, maior do que aquele a que se submetem os demais obreiros, como decorrência da atuação, sobre "relógio biológico" humano, do trabalho realizado em turnos diversos. 
Por isso, impositivo é que o trabalhador em tais condições faça jus aos intervalos intrajornada, para que disponham do necessário tempo para repouso e alimentação, o que lhes é efetivamente assegurado, tratandose inclusive de matéria sumulada pelo TST (Súmula $\mathrm{n}^{\mathrm{o}}$ 360 ), inclusive, sendo o casso de pagamento de horas extras, se tal não lhe for concedido pelo empregador.

Bem assim, a especificidade deste modo de exercer o labor enseja ao obreiro o direito às folgas constitucionalmente previstas no art. $7^{\circ}, \mathrm{XV}^{26}$, sem o que será o caso de aplicar-se também a estes trabalhadores o pagamento em dobro de tais dias laborados, conforme o disposto na Orientação Jurisprudencial no 410 da SDI-I do Tribunal Superior do Trabalho.

De outra parte, o empregado que labora em turnos ininterruptos de revezamento necessita prestar seus serviços em horários alternados, pelo que em diversas oportunidades o trabalho acontecerá em períodos noturnos, fazendo jus, pois, também ao adicional de serviço noturno, bem como à hora noturna reduzida (hora ficta) em turnos ininterruptos, consoante a OJ no 395 da SDI-I.

Controvérsia há quanto à jornada de trabalho dos empregados em regime de turnos ininterruptos de revezamento, estabelecida pela Constituição Federal em seis horas (artigo 7으. XIV). Afirma-se que a partir da $7^{\mathrm{a}}$ hora laborada, o trabalhador passa a ter direito a horas extras, consoante a orientação da S. 85 do TST. Inobstante, diverge a doutrina, que preconiza, ao invés, adote-se o divisor para cálculo do salário-hora (de 240 para 180).

\section{REFERÊNCIAS}

BRASIL. Constituição Federal. Disponível em: <http://www. planalto.gov.br/ccivil_03/constituicao/constituicao.htm>. Acesso em: 28 fev. 2014

BRASIL. Tribunal Superior do Trabalho. OJ 360 da SDI1, do TST. Disponível em: <http://www.tst.jus.br/ojs/-/asset publisher/ 1N7k/content/secao-de-dissidios-individuais-i-sdi-i?redirect $=$ http $\% 3 \mathrm{~A} \% 2 \mathrm{~F} \% 2 \mathrm{Fwww}$. tst.jus.br\%2Fojs $\% 3 \mathrm{Fp} \_\mathrm{p} \_\mathrm{id} \% 3 \mathrm{D} 101$ INSTANCE_1N7k\%26p_p_lifecycle\%3D0\%26p_p_state $\% 3$ Dnormal\%26p_p_mode $\% 3$ Dview $\% 26 p \_p \_c o l \_i d \% 3 D$ column$2 \% 26 p \_$p_col_count $\% 3 \mathrm{D} 2>$. Acesso em: $28 \mathrm{fev} .2014$.

DELGADO, Maurício Godinho. Curso de Direito do Trabalho. 9. ed. São Paulo: LTr, 2010.

DELGADO, Maurício Godinho. Curso de Direito do Trabalho. 10. ed. São Paulo: LTr, 2011. p. 852-855.

MARTINS, Sérgio Pinto. Direito do Trabalho. 29. ed. São Paulo: Atlas, 2013.

MARTINEZ, Luciano. Curso de Direito do Trabalho. 3. ed. São Paulo: Saraiva, 2012.

NASCIMENTO, Amauri Mascaro. Iniciação ao Direito do Trabalho. 36. ed. São Paulo: LTr, 2011.

\section{NOTAS}

1 Art. 7ำ São direitos dos trabalhadores urbanos e rurais, além de outros que visem à melhoria de sua condição social: (...) XIV - jornada de seis horas para o trabalho realizado em turnos ininterruptos de revezamento, salvo negociação coletiva; (...)

2 DELGADO, Maurício Godinho. Curso de Direito do Trabalho. 10. ed. São Paulo: LTr, 2011. p. 852-855.

3 OJ 360, da SDI1 do TST. Faz jus à jornada especial prevista no art. 7으, $\mathrm{XIV}$, da CF/1988 o trabalhador que exerce suas atividades em sistema de alternância de turnos, ainda que em dois turnos de trabalho, que compreendam, no todo ou em parte, o horário diurno e o noturno, pois submetido à alternância de horário prejudicial à saúde, sendo irrelevante que a atividade da empresa se desenvolva de forma ininterrupta.

4 DELGADO, Maurício Godinho. Curso de Direito do Trabalho. 10. ed. São Paulo: LTr, 2011. p. 852-855.

5 OJ 360, da SDI1 do TST.

6 DELGADO, Maurício Godinho. Curso de Direito do Trabalho. 10. ed. São Paulo: LTr, 2011. p. 852-855.

7 MARTINEZ, Luciano. Curso de Direito do Trabalho. 3. ed. São Paulo: Editora Saraiva, 2012. p. 330.

8 NASCIMENTO, Amauri Mascaro. Iniciação ao Direito do Trabalho. 36. ed. São Paulo: LTr, 2011. p. 288.

9 MARTINEZ, Luciano. Curso de Direito do Trabalho. 3. ed. São Paulo: Saraiva, 2012. p. 303.

10 DELGADO, Maurício Godinho. Curso de Direito do Trabalho. 9. ed. São Paulo: LTr, 2010. p. 868.

11 MARTINS, Sérgio Pinto. Direito do Trabalho. 29. ed. São Paulo: Atlas, 2013. p. 583 .

12 DELGADO, Maurício Godinho. Curso de Direito do Trabalho. 9. ed. São Paulo: LTr, 2010. p. 832.

13 DELGADO, Maurício Godinho. Curso de Direito do Trabalho. 9. ed. São Paulo: LTr, 2010. p. 832.
14 MARTINS, Sérgio Pinto. Direito do Trabalho. 29. ed. São Paulo: Atlas, 2013. p. 584.

15 DELGADO, Maurício Godinho. Curso de Direito do Trabalho. 9. ed. São Paulo: LTr, 2010. p. 831.

16 Art. 7ำ São direitos dos trabalhadores urbanos e rurais, além de outros que visem à melhoria de sua condição social:

$\mathrm{XV}$ - repouso semanal remunerado, preferencialmente aos domingos;

17 Art. 73. Salvo nos casos de revezamento semanal ou quinzenal, o trabalho noturno terá remuneração superior a do diurno e, para esse efeito, sua remuneração terá um acréscimo de $20 \%$ (vinte por cento), pelo menos, sobre a hora diurna.

$18 \S 1^{\mathrm{O}}$ A hora do trabalho noturno será computada como de 52 minutos e 30 segundos.

19 MARTINEZ, Luciano. Curso de Direito do Trabalho. 3. ed. São Paulo: Saraiva, 2012. p. 304.

20 MARTINS, Sérgio Pinto. Direito do Trabalho. 29. ed. São Paulo: Atlas, 2013. p. 585.

21 DELGADO, Maurício Godinho. Curso de Direito do Trabalho. 9. ed. São Paulo: LTr, 2010. p. 940.

22 Art. 468. Nos contratos individuais de trabalho só é lícita a alteração das respectivas condições por mútuo consentimento, e ainda assim desde que não resultem, direta ou indiretamente, prejuízos ao empregado, sob pena de nulidade da cláusula infringente desta garantia.

${ }^{23}$ XXXVI - a lei não prejudicará o direito adquirido, o ato jurídico perfeito e a coisa julgada.

${ }^{24}$ MARTINS, Sérgio Pinto. Direito do Trabalho. 29. ed. São Paulo: Atlas, 2013. p. 585.

25 MARTINS, Sérgio Pinto. Direito do Trabalho. 29. ed. São Paulo: Atlas, 2013. p. 585.

${ }^{26}$ Art. 7ำ São direitos dos trabalhadores urbanos e rurais, além de outros que visem à melhoria de sua condição social:

$\mathrm{XV}$ - repouso semanal remunerado, preferencialmente aos domingos. 